\title{
Quality of Life and Associated Factors of Cancer Patients in Malaysia: A review of current literature
}

\author{
Husna Ahmad Ainuddin*, Siti Norehan Ab Ghani, Akehsan Dahlan, Syamsul Anwar Sultan Ibrahim \\ Department of Occupational Therapy, Faculty of Health Science, UiTM Puncak Alam, 42300 Puncak Alam, Selangor, Malaysia
}

\begin{abstract}
Measuring quality of life provides information helpful for cancer patients. However, facts about the quality of life and its associated factors among cancer patients in Malaysia are inconclusive. The aim of this review of literature is to evaluate the quality of life of cancer patients and its associated factors. Based on this review of the literature, it identified 24 studies. Associated factors effecting quality of life of cancer patients include socio-demographic, health related, psychological and cancer treatment. In conclusion, there is a need for further research to focus on developing effective interventions to enhance the patients' quality of life.
\end{abstract}

(c) 2016. The Authors. Published for AMER ABRA by e-International Publishing House, Ltd., UK. Peer-review under responsibility of AMER (Association of Malaysian Environment-Behaviour Researchers), ABRA (Association of Behavioural Researchers on Asians) and cE-Bs (Centre for Environment-Behaviour Studies), Faculty of Architecture, Planning \& Surveying, Universiti Teknologi MARA, Malaysia.

Keywords: Quality of life; associated factors; cancer; Malaysia

\section{Introduction}

Cancer is an intricate, enervating and a common disease (Kashani et al., 2014a). A total of 18219 new cancer cases were diagnosed in 2007 while breast, colorectal and lung cancer were the top three most common cancers in Malaysia (NCR Malaysia, 2007). Indeed, cancer creates a serious national health concern and furthermore, it is becoming increasingly challenging to ignore the affected cancer patient with poor quality of life who needs more support and medical attention (Sharifa Ezat, Noraziani, \& Sabrizan, 2012).

The quality of life (QOL) is a multidimensional concept which has been used by a variety of disciplines in the research works of many nations (Mohit, 2014). In history, many QOL studies have tended to investigate objective indicators reflecting the human environment such as their employment data and the incidence of mortality and morbidity (Marans, 2012). Besides this, quality of life is also influenced by socioeconomic and psychological status, age and human traits (Martins, Duarte, \& Chaves, 2015).

\footnotetext{
*Corresponding author. Tel.: +0-000-000-0000

E-mail address: husnaa9866@puncakalam.uitm.edu.my
}

(c) 2016. The Authors. Published for AMER ABRA by e-International Publishing House, Ltd., UK. Peer-review under responsibility of AMER (Association of Malaysian Environment-Behaviour Researchers), ABRA (Association of Behavioural Researchers on Asians) and cE-Bs (Centre for EnvironmentBehaviour Studies), Faculty of Architecture, Planning \& Surveying, Universiti Teknologi MARA, Malaysia.

DOl: https://doi.org/10.21834/e-bpj.v1i2.257 
Because of the multidimensional concept of QOL, more clinicians are considering the importance of it as a critical aspect to cancer patients' care (Osoba, 1994; Young \& Maher, 1999; Morris, Perez \& McNoe, 1998).

Most forms of QOL assessments in oncology are characterized by a few distinct features. First, it is commonly recognized that quality of life is a multidimensional concept and is best measured using tools that look into a variety of domains of functioning and well-being (Cella \& Bonomi, 1995). Thus, most QOL instruments measure physical, social, and emotional aspects of functioning, common symptoms of cancer and its interventions (Leplege \& Hunt, 1997). Furthermore, due to the cureless nature of cancer, patients suffer side effects including pain, anorexia, depression and fatigue, which not only shorten life but also decrease the QOL (Sharifa Ezat, Noraziani, \& Sabrizan, 2012). However, interventions can produce direct effects on the patient's QOL for various possible reasons thus; these effects can in turn modify the patient's compliance and affect the risk of long-term complications of the disease (Sharifa Ezat, Norazian, \& Sabrizan, 2012). The decreased risk of long-term complications include increases in the amount of time during which the patient experiences better well-being, therefore, measuring QOL in cancer patients should take in attention all of these aspects (Kashani, Vaziri, Akbari, Mousavi, \& Far, 2014). Second, there is a general agreement that quality of life is a subjective phenomenon and that patients are the best judges of their own quality of life (Jacobsen, Davis, and Cella, 2002). A number of research articles suggest how clinicians can assess patient HRQOL more objectively by looking at symptoms and reporting on them, instead of the patient self-reporting (Bottomley, 2002). However Stephens et al. (1997) reported that there were significant differences between assessments carried out by clinicians when compared with self-report of patients. When compared, clinicians frequently under-assessed the level of functioning of the patient and under-reported symptoms that the patient actually reported. Therefore, the use of patient-reported questionnaires has become a standard practice in the assessment of cancer patient HRQOL. Third, in many cases, if well-validated instruments have not been used in the correct manner, there may be problems with correct interpretation (Green, 1997).

To this date, previous studies targeted the quality of life of patients with a few types of cancers using a variety of instruments and the results are limited and inconclusive. Thus, there is a need to review the quality of life of Malaysian cancer patients with respect to their clinical cancer diagnosis and its associated factors. The aim of the present study is to describe and summarize the quality of life of cancer patients and its associating factors in a large Malaysian community.

\section{Methods}

\subsection{Search strategies}

A comprehensive search was carried out using the following databases: Science Direct, MEDLINE, Scopus, Sage, Springer, Web of Science, Clinical Key and EBSCO. The following keywords were used: quality of life, associated factors, cancer and Malaysia. The search comprised primary and secondary studies and was limited to references published from 2011-2015. The references sections of the identified studies were also checked to retrieve other relevant work. Since this review aimed to identify associated factors related to QOL in cancer patients, cross-sectional and experimental studies were included.

\subsection{Inclusion and exclusion criteria}

Studies included in this review were those assessing the QOL of patients with a variety of cancer and also those dealing with symptom-related QOL, with standardized or validated questionnaires used to assess QOL or symptom-related QOL. Limits were placed on each search to exclude non-English citations and studies on nonhuman subjects or child subjects less than 15 years of age. Another factor considered is that the studies had to be conducted in Malaysia. Clinical trials were included if the QOL findings were reported and discussed. Articles were assessed and data extracted and synthesized. A variety of outcomes was considered by the authors. These addressed aspects of symptom control, patient and family or carer satisfaction and all aspects of QOL. Overall, 24 relevant studies were identified and included in the review.

\subsection{Identification of study characteristics}

All essential information and potential moderating factors was extracted from the selected studies: descriptive features of study context and research design, socio-demographic and clinical sample characteristics, type of QOL measurement and quantitative effects of intervention. 


\section{Results}

Based on this review of literature, it identified 19 cross-sectional studies, one prospective study, one quasi-experimental study and three randomized control trials. All 24 studies, with a total of 3022 participants, were published during the period 2011-2015. Areas of these studies were conducted in Malaysia. The participants included all type of cancer patients aged from 15 and above. The review was divided into two categories, cross-sectional and prospective and experimental studies.

Overall, the most common outcome measure used by the researchers to measure the quality of life was the European Organization for Research and Treatment of Cancer Quality of Life Questionnaire (EORTC QLQ-C30). Furthermore, a total of 8 quality of life measures were used throughout this review. These include Short Form Health Survey with 36 questionnaires (SF36), Global Health Status (GHS), Gastrointestinal Quality of Life Index (GIQLI), Hospice Quality of Life Index (HQLI), Euro Quality of Life-5 Dimensions (EQ-5D), WHO Quality of Life BREF (WHOQOL-BREF) and the Patient Generated Subjective Global Assessment (PG-SGA). Other outcome measures include psychological distress, functional and performance status, nutritional status, physical activity, neuro-psychiatry and patient's satisfaction. Below is the summary of each study included in the review.

Table 1. Summary of cross sectional studies

\begin{tabular}{|c|c|c|c|}
\hline $\begin{array}{l}\text { Author/year/ } \\
\text { country }\end{array}$ & Sample size & $\begin{array}{l}\text { Quality-of-life \& } \\
\text { relevant } \\
\text { instruments }\end{array}$ & Results \\
\hline \multirow[t]{2}{*}{ Isa et al. (2013) } & \multirow{2}{*}{$\begin{array}{l}\text { 193, prostate } \\
\text { cancer }\end{array}$} & 1. SF-36* & $\begin{array}{l}\text { 1. The associated factors with QOL and anxiety status were age, living } \\
\text { partner, intermittency and problem with hematuria. }\end{array}$ \\
\hline & & & $\begin{array}{l}\text { 2. QOL among prostate cancer patients with anxiety was lower compared } \\
\text { to non-anxiety. }\end{array}$ \\
\hline \multirow[t]{3}{*}{$\begin{array}{l}\text { Farooqui et al. } \\
\text { (2013) }\end{array}$} & \multirow[t]{3}{*}{$\begin{array}{l}\text { 393, all types of } \\
\text { cancer }\end{array}$} & $\begin{array}{l}\text { 2. EORTC } \\
\text { QLQ-C30* }\end{array}$ & $\begin{array}{l}\text { 1. Patients with better physical, emotional, role and cognitive status } \\
\text { experienced better HRQLL. }\end{array}$ \\
\hline & & 3. $\mathrm{GHS}^{*}$ & $\begin{array}{l}\text { 2. Patients having medical insurance and stable financial status showed } \\
\text { better quality of life scores. }\end{array}$ \\
\hline & & & $\begin{array}{l}\text { 3. Patients with bone cancer and very advanced stage cancer patients } \\
\text { showed the lowest GHS score. }\end{array}$ \\
\hline \multirow[t]{3}{*}{ Isa et al. (2012) } & \multirow[t]{3}{*}{$\begin{array}{l}\text { 193, prostate } \\
\text { cancer }\end{array}$} & \multirow[t]{3}{*}{$\begin{array}{l}\text { 1. SF-36 (PCS } \\
\text { and MCS) }\end{array}$} & $\begin{array}{l}\text { 1. The total quality of life score and the physical coefficient summary (PCS) } \\
\text { score was lower compared to mental coefficient summary (MCS). }\end{array}$ \\
\hline & & & $\begin{array}{l}\text { 2. The factors associated for PCS were age, living partner, renal problems, } \\
\text { and urinary problems of intermittency, dysuria and hematuria. }\end{array}$ \\
\hline & & & $\begin{array}{l}\text { 3. Meanwhile, the factors associated with MCS were age, living partner, } \\
\text { renal and urinary problems. }\end{array}$ \\
\hline \multirow[t]{3}{*}{ Zalina (2012) } & \multirow{3}{*}{$\begin{array}{l}70, \\
\text { gastrointestinal } \\
\text { cancer }\end{array}$} & 1. $I P A Q^{*}$ & \multirow{2}{*}{$\begin{array}{l}\text { 1. Increased in nutritional status among patients lead to better levels of } \\
\text { physical activity. }\end{array}$} \\
\hline & & 2. PG-SGA* & \\
\hline & & 3. GIQLI* & $\begin{array}{l}\text { 2. The better the nutritional status, the better the quality of life of the } \\
\text { survivors. }\end{array}$ \\
\hline \multirow[t]{3}{*}{ Lua et al. (2012) } & \multirow[t]{3}{*}{$\begin{array}{l}41 \text {, women with } \\
\text { breast cancer }\end{array}$} & $\begin{array}{l}\text { 1. EORTC } \\
\text { QLQ-C30 }\end{array}$ & \multirow[t]{3}{*}{$\begin{array}{l}\text { 1. Overweight or obese patients experienced higher cognitive functioning } \\
\text { and reported lower symptom score particularly for fatigue and insomnia. }\end{array}$} \\
\hline & & $\begin{array}{l}\text { 2. Body weight } \\
\text { status }\end{array}$ & \\
\hline & & 3. Diet history & \\
\hline \multirow{3}{*}{$\begin{array}{l}\text { Shahmoradi et al. } \\
\text { (2012) }\end{array}$} & \multirow{3}{*}{$\begin{array}{l}61 \text {, cancer } \\
\text { patients } \\
\text { receiving } \\
\text { hospice home } \\
\text { care }\end{array}$} & 1. ECOG* & \multirow{3}{*}{$\begin{array}{l}\text { 1. The most problem areas in these patients were in the domain of } \\
\text { functional well-being, followed by psycho physiological and social/spiritual } \\
\text { domain. } \\
\text { 2. Patients with advanced cancer have a diminished quality of life. }\end{array}$} \\
\hline & & 2. $\mathrm{HQLI}^{\star}$ & \\
\hline & & & \\
\hline Ooi \& Mazlina (2013) & 38, patients & 1. KPS* & 1. The Global Health Related QoL (HRQoL) and functional status of these \\
\hline
\end{tabular}




$\begin{array}{ll}\text { undergone } & \text { 2. MBI } \\ \text { neurosurgery. } & \text { 3. EORTC } \\ & \text { QLQ-C3O } \\ & \text { 4. EORTC BN- } \\ & 20^{*}\end{array}$

Matalqah et al.

(2011)

300 , women

with breast

cancer

patients showed improvement at six months after surgery.

2. Reduction in symptom burdens such as fatigue, nausea, vomiting, pain and headache were also noted at follow-up together with less future uncertainty.

3. Pearson correlation revealed a significant positive correlation between functional status and HRQoL at baseline and follow-up, in particular, global health status, physical functioning and role functioning.

1. EQ-5D mean index score was significantly lower for breast cancer survivors compared with the general comparative group with more problems with self-care, performing usual activities, pain or discomfort as well as anxiety or depression.

2. The HRQoL score was lower when comparing younger and older survivors to their age-matched peers.

Yusuf et al. (2013)

73 , Malay and

1. EORTC

Chinese

QLQ-C30

women with

breast cancer

2. EORTC

QLQ-BR23*

Priscilla et al.

105 ,

1. EORTC

(2011a)

hematological

QLQ-C30

cancer

Natrah et al. (2012)

100 , colorectal cancer

1. EORTC QLQ C-30

1. The Malay women had more symptoms such as nausea and vomiting, dyspnoea, constipation and breast-specific symptoms when compared to the Chinese.

1. Patients who earned a monthly wage of RM1000 or less had poorer physical function, more symptoms of pain, and more financial problems compared with patients who earned more.

1. Respondents role function significantly deteriorates with increasing stage of the disease

2. Pain, fatigue and dyspnoea had a significant difference between male and female, in which female experienced worse symptoms.

3. Less educated patients are likely to have the worse financial implication towards the disease.

Priscilla et al. (2011) 105,

hematological

cancer

1. MINI $6.0^{*}$

1. Major depression disorder affects majority domain of the quality of life,

2. EORTC

QLQ-C30

Magaji. et al. (2012)

20 , colon or

1. FACT-G*

rectal cancer

2. EORTC

QLQ-C30

3. EORTC

QLQ-LMC 21*

4. EORTC

QLQ-CR 29*

5. KPS*

Farooqui et al.

(2013a)

393, cancer

1. EORTC

patient of

QLQ-C30

Ramadas et al. oncology ward

40 , breast

1. WHOQOLcancer

BREF*

2. The main anxiety disorder that mostly correlated with quality-of-life scales was generalized anxiety disorder.

1. The result showed that the use of the Malay versions of EORTC QLQ C30, CR29 instruments are valid in colorectal cancer patients.
1. Global health score/quality of life was significantly different between Contemporary and Alternative Medicine users and non-users.

1. $85 \%$ of the survivors rated their QOL to be at least 'good' and only $7.5 \%$ of them were dissatisfied with their health.

2. Living with family and completion of treatment were significant predictive factors of self-rated QOL, while living with family and ever giving birth significantly predicted satisfaction with health and physical health.

3. Psychological health had moderate correlations with number of children and early cancer stage.

1. The quality of life for cancer patients undergoing palliative care based on domain score is highest on the domain of Role limitation (emotional) whereas the domain for bodily pain scored lowest on the quality of life
120 , general

1. PSQ $\|^{*}$

2. SF-36 


$\begin{array}{lll}\begin{array}{l}\text { Farooqui et al. } \\ (2012)\end{array} & \begin{array}{l}\text { 393, oncology } \\ \text { ward cancer } \\ \text { patients }\end{array} & \begin{array}{l}\text { 1. EORTC } \\ \text { QLQ-C30 }\end{array} \\ \begin{array}{l}\text { Abu Kassim et al. } \\ (2015)\end{array} & \begin{array}{l}\text { 80, breast } \\ \text { cancer }\end{array} & \begin{array}{l}\text { 1. FACT-G * } \\ \text { 2. FACT-B* }\end{array}\end{array}$

Sharifa Ezat et al. 105, colorectal 1. EORTC

(2014)

Azmawati et al.

(2014)

\section{QLQ-C30}

2. Questions on knowledge, awareness and practice

122, cervical 1. EORTCcancer experienced by cancer patients undergoing palliative care.

1. Socio-demographic factors including age and monthly house hold income were strongly correlated with MBCTs use.

2. HRQoL score shows significant difference in functional and symptoms scores among MBCTs users and non-users.

1. The results of the path analysis indicated the data support the interrelationships among the QOL subdomains for both Support Group and Control Group.

2. Emotional well-being and physical well-being were found to contribute more toward the functional well-being and the social well-being of those in the Support Group.

1. Cancer stage showed the most significant association with patients' quality of life with cognitive functioning, social functioning, pain and financial impact.

2. Although the mean scores for knowledge, awareness and practice were high, they were not associated with quality of life.

1. Global health status, emotional functioning and pain score were higher in stage III cervical cancer patients while role functioning was higher in stage I cervical cancer patients.

2. Patients with stage IV cancer have a lower mean score in global health status and emotional functioning while stage III had lower mean score in role functioning but higher mean score in pain.

3. Stage III and IV cervical cancers mainly affect the QOL of cervical cancer patients.

* List of outcome measures:

1. European Organization for Research and Treatment of Cancer Quality of Life Questionnaire (EORTC QLQ-C30), 2. Short Form Health Survey with 36 questionnaires (SF-36), 3. Depression, Anxiety and Stress Scale Short Form 21 (DASS-21), 4. Global Health Status (GHS), 5. Gastrointestinal Quality of Life Index (GIQLI), 6. International Physical Activity Questionnaire-short Form (IPAQ), 7. Eastern Cooperative Oncology Group performance scale (ECOG), 8. Hospice Quality of Life Index (HQLI), 9. Karnofsky Performance Scale (KPS), 10. Modified Barthel Index (MBI), 11. EORTC Brain Cancer Module (BN-20), 12. Euro Quality of Life-5 Dimensions (EQ-5D), 13. Visual Analog Scale (EQVAS), 14. EORTC Breast Cancer Specific (BR-23), 15. Mini-International Neuro-psychiatric Interview version 6.0 (MINI 6.0), 16. Functional Assessment of Cancer Therapy-General (FACT-G), 17. EORTC QLQ colorectal cancer liver metastasis (LMC 21), 18. EORTC QLQ Colorectal Cancer (CR29), 19. Functional Assessment of Cancer Therapy-Breast Cancer (FACT-B), 20. WHO Quality of Life BREF (WHOQOL-BREF), 21. Patient Satisfaction Questionnaire III (PSQ III), 22. Piper Fatigue Scale (PFS), 23. Schwartz Cancer Fatigue Scale (SCFC-6), 24. Baseline Hospital Anxiety and Depression Scale (HADS), 25. Patient Generated Subjective Global Assessment (PG-SGA)

Table 2. Summary of experimental studies

\begin{tabular}{|c|c|c|c|}
\hline $\begin{array}{l}\text { Author/year/ } \\
\text { country }\end{array}$ & Sample size & $\begin{array}{l}\text { Quality-of-life \& } \\
\text { relevant instruments }\end{array}$ & Results \\
\hline $\begin{array}{l}\text { Biswal et al. } \\
\text { (2013) }\end{array}$ & $\begin{array}{l}100 \text { (50 study arm, } \\
50 \text { control arm), } \\
\text { breast cancer }\end{array}$ & $\begin{array}{l}\text { 1.EORTC QLQ-C30 } \\
\text { 2. PFS* } \\
\text { 3. SCFC-6* } \\
\text { 4. ECOG* } \\
\text { 5. HADS* }\end{array}$ & $\begin{array}{l}\text { 1. The study found that the fatigue scores among patients in } \\
\text { the control group are higher compared with the study groups } \\
\text { of patients receiving Withania somnifera. }\end{array}$ \\
\hline Law et al. (2014) & $\begin{array}{l}60 \text { ( } 30 \text { intervention } \\
\text { group, } 30 \text { control } \\
\text { group), stage } 3 \text { and } 4 \\
\text { breast cancer }\end{array}$ & $\begin{array}{l}\text { 1. EORTC QLQ-C30 } \\
\text { 2.EORTC QLQ BR } 23\end{array}$ & $\begin{array}{l}\text { 1. There were significant mean score differences for } \\
\text { functioning and global QOL between groups. } \\
\text { 2. Patients who were using virgin coconut oil as a supplement } \\
\text { had better scores for symptoms compared to the patients who } \\
\text { were not using VCO. }\end{array}$ \\
\hline
\end{tabular}




\begin{tabular}{clll}
\hline Lua et al. (2014) & $\begin{array}{l}60 \text { (30 intervention } \\
\text { group, 30 placebo } \\
\text { group), breast cancer }\end{array}$ & $\begin{array}{l}\text { 1.VAS nausea score } \\
\text { 2. Frequency of } \\
\text { vomiting } \\
\text { 3. EORTC QLQ-C30 }\end{array}$ & $\begin{array}{l}\text { 3. A 10 points improvement on role functioning and appetite } \\
\text { loss was also documented while patients were on ginger } \\
\text { essential oil. }\end{array}$ \\
Isa et al. (2013a) & $\begin{array}{l}155 \text { (77 intervention } \\
\text { group, 78 } \\
\text { comparison group), } \\
\text { prostate cancer }\end{array}$ & $\begin{array}{l}\text { 1.SF-36 The study found that the Applied Progressive Muscle } \\
\text { Relaxation Training (APMRT) significantly increase the score } \\
\text { of MCS and QOL among prostate cancer patients. }\end{array}$ \\
\hline
\end{tabular}

\section{Discussions}

\subsection{Quality of life of cancer patients}

The problem of the quality of life is a multidimensional phenomenon which relates with social, cultural, psychological and environmental factors. Therefore, there is a crucial need for a holistic approach in reaching a fair and enduring solution as far as the quality of life is concerned (Keles, 2012). In cancer patients, (Degi, 2013) found that quality of life tends to be significantly related to low education, marital status, type of cancer malignancy, stage, poor health status, physical inactivity, and severe depression. Nevertheless, increased quality of life can be seen in patients with good family support, early stage cancer development and stable psychological status (Maltaqah, Radaideh, Awaisu, \& Yusoff, 2011; Farooqui et al., 2013).

\subsection{Socio-demographic factors}

The quality of life had a significant relationship with age and gender of cancer patients (Isa et al., 2012; Priscilla et al., 2011). A study reported that older colorectal cancer patients had better QOL in terms of emotional and social functioning (Sharifa Ezat et al., 2014). Additionally, another study found that women had better quality of life when compared to men (Farooqui et al., 2013). Besides age and gender, race also plays an important role in patients QOL. A reviewed article also reported that Indian respondents had the highest score for global health status while the Chinese had the lowest score (Sharifa Ezat et al., 2014). However, when compared between Malay and Chinese breast cancer survivors, it was reported that the Malays had had greater symptoms of nausea, vomit, dyspnea, constipation and thus translated to a poorer quality of life compared to Chinese women (Yusuf A. et al., 2013). In terms of marital status it was found that married women experienced better HRQOL and less fatigue compared to unmarried woman (Lua, Salihah, \& Mazlan, 2012). This was also supported by a study in which married cancer survivors had higher physical health compared to singles (Ramadas et al., 2015). Moreover, those who stayed with family had higher physical and psychological health scores (Isa et al., 2012). However, another group of scholars found it otherwise; in which divorced participants had better global health scores (Farooqui et al., 2013).

Quality of life in cancer patients also had a significant relationship with their financial status. Result from a study found that, patients who earned a monthly wage of RM1000 or less had reduced physical function, more symptoms of pain and more financial difficulties compared with patients who earned more (Priscilla et al., 2011). Patients having medical insurance and stable financial status showed better quality of life scores (Farooqui et al., 2013). Additionally, patients who are economically affected by cancer are more likely to delay further medical treatment and cause their disease becoming uncontrollable thus result in the poor quality of life.

\subsection{Health-related factors}

Cancer patients experienced a range of symptoms which includes pain, nausea and vomiting, lack of appetite and physical discomfort that are persistent and results in a negative impact on patients' quality of life (Ooi \& Mazlina, 2013; Matalqah et al., 2011; Natrah et al., 2012). Additionally, fatigue was one of the symptoms that trigger emotional pressure among cancer patients (Priscilla et al., 2011). In terms of cancer stage, most of the studies have identified that patients with advanced-stage cancer have diminished their total quality of life (Lua et al., 2012; Ramadas et al., 2015; Shahmoradi, Kandiah, \& Loh, 2012). 
Furthermore, a study found that Stage III and stage IV cervical cancers mainly affect almost all the domain quality of life compared with early stage patients with cervical cancer (Azmawati et al., 2014). In addition to that, it could also be seen that patients with bone cancer and very advanced stage cancer showed the lowest global health status scores (Farooqui et al., 2013). As the disease progresses, it will bring more discomforting symptoms and pain to the patients, thus in return decreases their quality of life.

Researchers reported that physical activity and QOL showed a negative correlation with nutrition status indicating better nutritional status with better QOL (Zalina A. Z., Lee V. C. \& Kandiah M., 2012). The study also showed a significant relationship between physical activity and nutritional status, indicating that the better the nutritional status, the higher physical activity carried out. However, another study reported that dietary intakes was found to be not correlated with quality of life but patients with greater body mass index had better emotions and experienced lower symptoms particularly for fatigue and insomnia (Lua et al., 2012).

Two studies in the review investigated functioning in cancer patients (Maltaqah et al., 2011; Ooi \& Mazlina M., 2013). Scholars reported that twice as many respondents with breast cancer reported having problems with self-care such as dressing and taking baths and performing usual activities such as work, study, leisure and housework compared to their peers (Maltaqah et al., 2011). However, after a surgical intervention among primary intracranial tumor patients, researchers found that there were significant positive relationships between QOL and functioning (Ooi \& Mazlina, 2013). Nonetheless, cancer patients stilled looked forward to doing hobbies as it was a way to cope with the disease (Saarelainen S., 2012).

\subsection{Psychological factors}

Distress is an unpleasant multidimensional emotional experience that may interfere with physical symptoms, the treatment process, affect the ability to cope with cancer and decreases the patients' quality of life (Kashani, F. L. et al., 2014; Ursaru, M., Crumpei, I. \& Crumpei, G., 2014; Isa, M. R. et al., 2013; Priscilla D. et al., 2011). Most of the cancer survivors were under mental, physical or emotional pressure which includes anxiety and depression (Maltaqah L. M. et al., 2011). There were various factors responsible for the cause of depression or emotional disturbances in cancer disease population. The disease symptom, financial concerns, social, cognitive and emotional impairment can contribute to the development of major depression or anxiety. Younger patients however, tend to have difficulties in performing their responsibilities toward work and family that could eventually lead to psychological stress compared to the older patients (Farooqui, M. et al. 2013).

\subsection{Interventions and quality of life}

Due to the intricacy of the disease and the impact it has on the life of the patient, cancer, and cancer treatments are now thought to fit within a biopsychosocial model of health and illness (Sarafino, 2006). The biopsychosocial models of health and illness address biological, psychological, behavioral and social factors that interrelate with one another, and affect overall health (Papasteri \& lulian, 2015). One study used Ginger essential oil to treat chemotherapy-induced nausea and vomiting. The ginger essential oil has been used in Asian countries as a remedy for many medical conditions such as headaches and Nausea. The study discovered that there were significant differences for symptoms of vomiting over a five day treatment period, in which the vomiting of cancer patients decreased after inhaling the ginger essential oil (Lua et al., 2014). Additionally, patients' HRQoL increased while they inhaled the ginger essential oil throughout the course of cancer treatment.

Meanwhile, researchers examined the use of Withania Somnifera, a common medicinal herb grown in Asia as a substance to reduce fatigue in chemo-cancer patients (Biswal et al., 2013). Their study showed that there was a significant difference on fatigue between the study and control group in which the study group had less fatigue after the administration of Withania somnifera in the course of chemotherapy. Furthermore, there were significant differences in symptoms which include fatigue, physical functioning, role functioning, insomnia, pain emotional functioning, social functioning and global health status. It could be seen that the study group had less of the symptoms thus a better quality of life compared to the control group. On the other hand, a study was conducted a randomized control trial to investigate the virgin coconut oil as a supplement among breast cancer patients (Law et al., 2014). Their study showed that all aspects of functioning showed improvement over time, and every functioning had higher values in the intervention group compared with the control group at the last chemotherapy session. However, in terms of symptoms assessment there were no significant differences between groups. 
Besides using herbal intervention for cancer patients, a clinical trial using the Applied Progressive Muscle Relaxation Training (APMRT) was conducted (Isa et al., 2013). Overall, there was a significant change over time in the overall QOL of the cancer patients. In addition to this, a study piloted a survey on the use of Mind Body Complementary Therapies (MBCTs) in the course of treatment for cancer patients and the normal population (Farooqui et al., 2013a). The results showed that socio-demographic factors including age and monthly household income were strongly correlated with MBCTs use. Furthermore, HRQoL scores show significant difference in functional and symptoms scores among MBCTs users and non-users.

Lastly, the effectiveness of a support group intervention among cancer survivors was examined (Abu Kassim et al., 2015). Measurements were taken pre and post intervention sessions. The results showed that physical well-being and emotional wellbeing were found to be significant positive predictors of functional well-being for both the support and controlled group. The influence of physical, emotional and functional well-being on social well-being is also greater for the support group than the control group. It could be evidence that social support is another factor that is very effective on perception of symptoms severity as well as the quality of life of patient, because the individual's quality of confronting the stress is highly under effect of social support receiving manner (Taheri, Ahadi, Kashani, \& Kermani, 2014).

\subsection{Limitation and implication}

The review has certain limitations. The study design of 19 studies was cross-sectional reflecting a low grade of evidence. Additionally, the criteria adopted for including associations in the discussion might have excluded results that were clinically significant but did not reach statistical significance.

As for the implication of the review, it could be noted that the quality of life of cancer patients is influenced by many factors. Thus, policy makers and healthcare providers should acknowledge these factors and in-cooperate a holistic approach for the support and medical care of these cancer patients.

\section{Conclusion and Recommendation}

In conclusion, the most widely used QOL instrument was the EORTC QLQ-C30. The use of a valid and correct measurement can insure that the results are accurate and the needed information is obtained. To enable the best care for cancer patients, comprehensive outcome data is vital and should be the focus of future research.

Meanwhile, the associated factors that affect quality of life cancer patients in Malaysia were because of a range of symptoms that are discomforting and persistent, socio-demographic backgrounds of the patient, psychological stress, treatments and health-related. These results may support clinicians to plan better provision of current limited resources to those most in need. Family dynamics and patient's social life received less attention in quality of life studies. There is a need to explore these issues more expansively, since cancer patients have indicated that family is an important aspect of their QOL. Lastly, it is recommended that there is further research to focus on developing appropriate and effective interventions in order to reduce the negative health-related and psychological factors and to enhance the patients' quality of life.

\section{Acknowledgments}

The authors wish to thank the Research Management Centre of UiTM and the Ministry of Education for the permission to publish this paper and their invaluable support towards this study. This study were funded by the Fundamental Research Grant Scheme [FRGS 600-RMI/FRGS 5/3 (29/2014)] under the Ministry of Education Malaysia.

\section{References}

Abu Kassim, N.L., Mohd Hanafiah, K., Samad-Cheung, H., \& Rahman, M.T. (2015). Influence of support group intervention on quality of life of Malaysian breast cancer survivors. Asia-Pacific Journal of Public Health, 27(2), 495-505. 
Biswal, B.M., Sulaiman, S.A., Ismail, H.C., Zakaria, H., \& Musa, K.I. (2013). Effect of Withania somnifera (Ashwagandha) on the development of chemotherapyinduced fatigue and quality of life in breast cancer patients. Integrative Cancer Therapies, 12(4), 312-22.

Bottomley, A. (2002). The cancer patient and quality of life. The Oncologist, 7, 120-125.

Cella, D.F., \& Bonomi, A.E. (1995). Measuring quality of life: 1995 update. Oncology, 9(suppl. 11), 47-60.

Degi, C.I. (2013). Psychosocial aspects of cancer in hospitalized adult patients in Romania. Procedia-Social and Behavioral Sciences, 82, 32 - 38.

Farooqui, M., Hassali, M., Knight, A., Akmal, A., Farooqui, M.A., \& Saleem, F. (2012). PCN31 A Cross-sectional assessment of the quality of life of cancer patients and their Complementary and Alternative Medicines (CAM) Use. Value in Health, 15(7), A658.

Farooqui, M., Hassali, M., \& Knight, A. (2013). Cross sectional assessment of Health Related Quality of Life (HRQL) among patients with cancer in Malaysia. Asian Pacific Journal, 5, 3017-3021.

Farooqui, M., Hassali, M.A., Abdul Shatar, A.K., Shafie, A., Farooqui, M.A., Saleem Haq, M., Ayob, A., \& Othman, C.N. (2013a). Use of Mind Body Complementary Therapies (MBCTs) and Health Related Quality of Life (HRQOL) of cancer patients. ASEAN Journal of Psychiatry, 14(1), 40-50.

Green, S.B. (1997). Does assessment of quality of life in comparative cancer trials make a difference? A discussion. Control Clinical Trials, 18, 306-310.

Isa, M.R.B., Ming, M.F., Razack, A.H.A., Zainuddin, Z.M., \& Zainal, N.Z. (2012). General health related quality of life and associated factors among prostate cancer patients in two tertiary medical centers in Kuala Lumpur, Malaysia: A cross-sectional study. Asian Pacific Journal of Cancer Prevention, 13(12), 59996004.

Isa, M.R., Moy, F.M.., Abdul Razack, H., Zainuddin, Z.M., \& Zainal, N.Z. (2013). Anxiety status and its relationship with general health related quality of life among prostate cancer patients in two university hospitals in Kuala Lumpur, Malaysia. Iran Journal of Public Health, 42(3), 240-248.

Isa, M.R., Moy, F.M., Razack, A.H.A., Zainuddin, Z.M., \& Zainal, N.Z. (2013a). Impact of applied progressive deep muscle relaxation training on the health related quality of life among prostate cancer patients--a quasi experimental trial. Preventive Medicine, 57, 37-40.

Jacobsen, P.B., Davis, K., \& Cella, D. (2002). Assessing quality of life in research and clinical practice. Oncology.

Kashani, F. L., Vaziri, S., \& Akbari, M. E. (2014). The effectiveness of creating hope on distress of women with breast cancer. Procedia-Social and Behavioral Sciences, 159, 201-205.

Kashani, F.L., Vaziri, S., Akbari, M.E., Jamshidifar, Z., \& Sanaie, H. (2014a). Stress coping skills training and distress in women with breast cancer. ProcediaSocial and Behavioral Sciences, 159, 192-196.

Kashani, F.L., Vaziri, S., Akbari, M E., Mousavi, S.M. \& Far, N.S. (2014b). Effectiveness of four-factor psychotherapy in decreasing distress of women with breast cancer. Procedia-Social and Behavioral Sciences, 159, 214-218.

Keles, R. (2012). The quality of life and the environment. Procedia-Social and Behavioral Sciences, 35, 23-32.

Law, K.S. et al. (2014). The effects of Virgin Coconut Oil (VCO) as supplementation on Quality of Life (QOL) among breast cancer patients. Lipids in Health and Disease, 13(139).

Leplege, A, \& Hunt S. (1997). The problem of quality of life in Medicine. JAMA, 278, 47-50.

Lua. P.L., Salihah, N.Z., \& Mazlan, N. (2012). Nutritional status and health-related quality of life of breast. Malaysian Journal of Nutrition, 18(2), $173-184$.

Lua, P.I., Salihah, N., \& Mazlan, N. (2015). Effects of inhaled ginger aromatherapy on chemotherapy-induced nausea and vomiting and health-related quality of life in women with breast cancer. Complementary Therapies in Medicine, 23, 396-404.

Magaji, B., Moy, F., Roslani, A., Sagap, I., Zakaria, J., Blazeby, J.M., \& Law, C. (2012). Health-related quality of life among colorectal cancer patients in Malaysia: a study protocol. BMC Cancer, 12(1), 384.

Marans, R.W. (2012). Quality of urban life studies: An overview and implications for environment-behaviour research. Procedia-Social and Behavioral Sciences, $35,9-22$.

Martins, C., Duarte, J., \& Chaves, C. (2015). Contributions to the quality of life of chronic renal insufficient patients. Procedia-Social and Behavioral Sciences, 165, 144-151. 
Matalqah, L.M., Radaideh, K.M., Yusoff, Z.M., \& Awaisu, A. (2011). Health-related quality of life using EQ-5D among breast cancer survivors in comparison with age-matched peers from the general population in the state of Penang, Malaysia. Journal of Public Health, 19(5), 475-480.

Mohit, M.A. (2014). Present trends and future directions of quality of life. Procedia-Social and Behavioral Sciences, 153, 655-665.

Morris, J., Perez, D., \& McNoe, B. (1998). The use of quality of life data in clinical practice. Quality of Life Research, 7, 85-91.

National Cancer Registry Malaysia (2007). Ministry of Health Malaysia.

Natrah, M.S., Ezat, S.W.P., Syed, M.A., Rizal, A.M.M., \& Saperi, S. (2012). Quality of life in Malaysian colorectal cancer patients: A preliminary result. Asian Pacific Journal of Cancer Prevention, 13(3), 957-962.

Ooi, A.L., \& Mazlina, M. (2013). Functional status and health-related quality of life in patients with primary intracranial tumour. The Medical Journal of Malaysia, $68(6), 448-452$

Osoba, D. (1994). Lessons learned from measuring health-related quality of life in Oncology. Journal of Clinical Oncology, 12, 608-616.

Papasteri, C., \& lulian, A. (2015). Tailoring a multicomponent - psychotherapy and dietary -intervention to cancer patient needs. Procedia - Social and Behavioral Sciences, 187, $118-123$.

Priscilla, D., Hamidin, A, Azhar, M.Z., Noorjan, K.O., Salmiah, M.S., \& Bahariah, K. (2011). Assessment of depression and anxiety in haematological cancer patients and their relationship with quality of life. East Asian Archives of Psychiatry: Official Journal of the Hong Kong College of Psychiatrists = Dong Ya Jing Shen Ke Xue Zhi: Xianggang Jing Shen Ke Yi Xue Yuan Qi Kan, 21(3), 108-114.

Priscilla, D., Hamidin, A., Azhar, M.Z., Noorjan, K., Salmiah, M.S., \& Bahariah, K. (2011a). The socio-demographic and clinical factors associated with quality of life among patients with haematological cancer in a large government hospital in Malaysia. Malaysian Journal of Medical Sciences, 18(3), 49-56.

Ramadas, A., Qureshi, A.M., Dominic, N.A., Botross, P., Riad, A., Jayanthi, V., \& Arasoo, T. (2015). Socio-Demography and medical history as predictors of health-related quality of life of breast cancer survivors. Asian Pacific Journal of Cancer Prevention, 16, 1479-1485.

Sarafino, E.P. (2006). Health psychology: Biopsychosocial interactions (5th ed.). New York: John Wiley \& Sons.

Sharifa Ezat, W.P., Noraziani, K., \& Sabrizan, O. (2012). Improving quality of life among cancer patients in Malaysia. Asian Pacific Journal of Cancer Prevention, 13.

Saarelainen, S. (2012). Positive adjustment to cancer meaning of inner design and external support. Procedia -Social and Behavioral Sciences, $45,54-64$.

Sharifa Ezat, W.P. S., Khairudin, S., Kabinchong, C., Musa, N., Joo, C., Saad, N., \& Omar, N. (2014). Relationship of Knowledge, Attitude , Practice (KAP) and Demographic factors with quality of life among urban colorectal cancer patients in Malaysia. Middle East Journal of Cancer, 5(1), 31-41.

Sharifa Ezat, W.P., Fuad, I., Hayati, Y., Zafar, A., \& Kiyah, G.A.W. (2014a). Observational study on patient's satisfactions and Quality of Life ( QoL ) among cancer patients receiving treatment with palliative care intent in a tertiary hospital in Malaysia. Asian Pacific Journal of Cancer Prevention, 15(2), 695-701.

Shahmoradi, N., Kandiah, M., \& Loh, S.P. (2012). Quality of life and functional status in patients with advanced cancer admitted to hospice home care in Malaysia: A cross-sectional study. European Journal of Cancer Care, 21(5), 661-666.

Stephens, R.J., Hopwood , P., Girling, D.J. et al. (1997). Randomized trials with quality of life endpoints: are doctors' ratings of patients' physical symptoms interchangeable with patients' self-ratings? Quality of Life Research, 6, 225-236.

Taheri, A., Ahadi, H., Kashani, F.L., \& Kermani, R.A. (2014). Mental hardiness and social support in life satisfaction of breast cancer patients. Procedia - Social and Behavioral Sciences, 159, 406 - 409.

Ursaru, M., Crumpei, I., \& Crumpei, G. (2014). Quality of life and religious coping in women with breast cancer. Procedia - Social and Behavioral Sciences, 114, $322-326$.

Young, T., \& Maher, J. (1999). Collecting quality of life data in EORTC clinical trials—what happens in practice? Psycho-Oncology, 8, $260-263$.

Yusuf, A., Ab Hadi, I.S., Mahamood, Z., Ahmad, Z., \& Keng, S.L. (2013). Quality of life in Malay and Chinese women newly diagnosed with breast cancer in Kelantan, Malaysia. Asian Pacific Journal of Cancer Prevention, 14(1), 435-440. 
Ahmad Ainuddin, H., et al. / 2nd AQoL2015lzmir, Turkey, 09-14 Dec. 2015 / E-BPJ, 1(2) July 2016 (Pp. 76-86)

Zalina, A.Z., Lee, V.C., \& Kandiah, M. (2012). Relationship between nutritional status, physical activity and quality of life among gastrointestinal cancer survivors. Malaysian Journal of Nutrition, 18(2), 255-264. 